\title{
COMPREHENSIVE EVALUATION OF TECHNOLOGICAL MEASURES FOR INCREASING AVAILABILITY OF WOOD RESOURCES
}

\author{
Marija Olegovna Pozdnyakova, Aleksandr Petrovich Mokhirev", Tatyana Georgievna Ryabova \\ Lesosibirsk Branch of Reshetnev Siberian State University of Science and Technology Lesosibirsk, \\ Russian Federation
}

The purpose of the work is to develop technological measures that make it possible to increase the availability of wood resources in a certain area of the forest reserves with the minimum expenditure of resources (financial, labor, material). The results of research of theoretical and methodical bases of availability of wood resources have been provided; the following five key types have been identified: ecological, transport, technical, technological and economic availability. On the basis of factor analysis of wood availability, the following technological measures aimed at the most effective wood availability management have been developed: the involvement of wood waste in the production process of an enterprise with the purpose of additional products manufacture; selection of the optimal system of logging machines; selection of the optimal route for wood raw materials transportation using the minimum cost method. For approbation of the developed measures, the Gremuchinskoe logging site of the Novoyeniseiskiy Wood-Chemical Complex CJSC, located in Krasnoyarsk Territory, was selected. The average annual volume of raw materials harvested for sawing in this area is $240,000 \mathrm{~m} 3$. The primary assessment of the availability of wood raw materials showed that more than $66 \%$ of the total stock of raw materials (by volume) in the specified area is unavailable for efficient industrial development. The introduction of the developed measures allowed reducing this indicator to the level of $23.84 \%$.

Key words: Availability; Wood resources; Technology; Raw materials; Wood transportation; Profitability

\section{INTRODUCTION}

The term "availability of wood resources" is increasingly found in the studies of modern scientists [1, 2, 3, 4]. Tretyakov [1] believes that economic availability cannot be considered separately from environmental availability; R.V. Polshvedkin and A.N. Mariev [4] suggest moving away from cost estimates and determining the economic availability of wood resources in relative values (classes). However, no scientist has presented an unambiguous definition of this concept. The availability of wood resources is a broad concept that includes many different indicators, but ultimately characterizes the viability of the logging industry. First of all, sustainable wood production means high profitability, ensuring the competitiveness of wood products in the market. Thus, the availability of wood resources is a key factor in creating an efficient and stable wood industry complex. During the study of theoretical and methodological foundations of this issue, the authors identified 5 types of wood availability: ecological, technological, technical, transport, and economic [3].

Most often, the increase of comprehensiveness of the use of raw materials for obtaining additional products is suggested to be the measure to increase the availability of wood resources. A.G. Tretyakov and G.A. Knyazev [1, 4, 5] develop the idea of producing pellets of cull lumber and sawmill wastes as products with the highest added value. Also, the optimization of transport costs is considered to be a popular way of increasing the availability of wood, which is re- flected in the works of M.A. Efremov and A.P. Mokhirev [6, 7]. Thus, in the conditions of limited resources of production entities, it becomes necessary to analyze and identify the most effective measures to increase the availability of wood resources.

\section{OBJECTS AND METHODS OF RESEARCH}

During the analysis of various ways to increase the availability of wood resources and their effectiveness [8], the authors identified several activities that have the greatest efficiency: involving wood waste in the production of additional products, optimizing transport costs, selecting the optimal machine system.

The purpose of the commercial products portfolio formation is complex and multi-variant: when the amounts of raw materials are limited, it is necessary to get the products with the greatest commodity value and minimum production costs. In addition, the volume of production should not exceed the volume of market demand. To solve this problem, methods of economic and mathematical modeling are used [9].

Data is determined on the basis of the results of marketing research of the market of wood products in the region, as well as on the basis of inflation data adjustments obtained directly at the plant. Costs for the production of each type of product are determined on the basis of estimated standards and analysis of market prices for raw materials, equipment, fuel and energy resources and

* Lesosibirsk Branch of Reshetnev Siberian State University of Science and Technology Lesosibirsk, Russian Federation, 
workers' wages. The rates of raw materials consumption for the manufacture of various products are also determined.

The production capacity of the enterprise is limited by the productivity of chippers for wood waste grinding. The maximum annual output of the product type $\mathrm{i}(A)$ is determined. Having the initial data, we can formulate the optimization problem. The following are accepted as the elements of the problem solution: $V_{i}$ - the volume of raw material used for the production of the product type i, $\mathrm{m}^{3}$; $X_{i}$ - the volume of production of the product type $i$.

Limitations on production capacity will be: $X_{i} \leq A_{i} \ldots X_{n} \leq A_{n}$, where $n$ is the number of different types of products.

The consumption of raw materials for the production of all products will be: $V_{i} X_{1}+\ldots+V_{n} X_{n}$

The consumption of raw materials cannot exceed the reserves of raw materials in the cutting area $-\mathrm{S}, \mathrm{m}^{3}$. Thus, we obtain the following limitation: $V_{i} X_{1}+\ldots+V_{n} X_{n} \leq S$.

The objective function of this problem will look like:

Function $F_{1}$ - profit from sales of all products, monetary unit;

$F_{1}=P_{i} X_{1}+\ldots+P_{n} X_{n} \rightarrow \max$

Where $P_{i}$ is the price per unit of the product type $i$ in monetary units.

Based on the above, we obtain a mathematical model of

$$
\begin{gathered}
F_{1}=P_{i} X_{1}+\ldots+P_{n} X_{n} \rightarrow \max \\
\left\{\begin{array}{l}
X_{i} \leq A_{i} \\
\ldots \\
X_{n} \leq A_{n} \\
V_{i} X_{i}+\ldots+V_{n} X n \leq S
\end{array}\right. \\
X_{1} \geq 0 ; \quad X_{2} \geq 0 ; \quad X_{3} \geq 0
\end{gathered}
$$

production planning:

As a result of the solution of the problem, a model of the maximum efficient use of logging wastes will be obtained.

It is assumed that currently the logging waste of the enterprise is not involved in the production process as a raw material. The environmental aspect of the activity is that the enterprise will increase the complexity of the use of wood resources.

To implement the measures aimed at improving the technological process of logging, the method of forming an effective system of logging machines is used [10]. This technique is based on the selection of the basic machine and auxiliary machines.

The initial data for solving the problem of forming a system of machines are the natural conditions of the terrain where the machinery operates, production conditions imposed by the efficiency of the enterprise's activity and the technical and economic indicators of the machinery to be selected for a place in the machine system.

Natural conditions shall mean such limiting factors as: the prevailing slope of the terrain iterr; ground bearing capacity $\partial_{\text {ground }}$; average diameter of the growing stock $\mathrm{d}_{\text {average }}$, and ambient temperature $\mathrm{T}_{\text {min }}, \mathrm{T}_{\max }$.

Production conditions, such as: the planned machine output per shift $Q_{\text {pl.mach }}$; planned logging site output per shift $Q_{\text {pl...s. }}$, as well as the maximum investment $K_{\max }$.

The technical and economic indicators of the machines in question are: maximum operational inclination $i_{\text {max }}$, specific ground pressure $\partial_{\text {mach }}$, diameter processed by the attachment $\mathrm{d}_{\text {pr.attacment, }}$ operating range of ambient temperature $t_{\min }, t_{\max }$, shift output $\mathrm{O}_{\text {shift }}$, price $\mathrm{C}$, number of basic machines $n_{\text {basic }}$.

When all the initial data for the subsequent calculations are available, the basic machine is selected.

The priority of the choice of the basic machine is determined by the priority of its actions compared to other participants in the technological process. Thus, the auxiliary machines shall be selected to meet the characteristics of the basic machine. The selection of the basic machine takes place in two stages.

First of all, there shall take place the selection of machines that satisfy the excluding limitations. Excluding limitations shall mean restrictions imposed by the natural production conditions under which the machine is capable of conducting logging operations.

Second of all, significant indicators shall be used to make a selection. Significant indicators are technical and operational indicators of candidates for a place in the machine system, which cannot be neglected if they do not meet the stated requirements.

If the characteristics of the basic machine correspond to the given limitations imposed by natural production conditions, you can proceed to the choice of auxiliary machines. As in the case of the basic machine, the technical and economic characteristics of the auxiliary machines must satisfy the excluding and significant limitations. If several machine systems are obtained in the course of work, their comparative analysis shall be carried out.

Analysis of the obtained systems of logging machines is made by the criterion of investment efficiency $\mathrm{E}_{\text {inv }} \rightarrow$ max. When calculating the investment efficiency, the following initial data are used: 1) the annual volume of the harvest is the volume of harvested wood that is established based on the estimated logging area of the logging site; 2 ) the variable volume is set depending on the shift output of the equipment; 3 ) the number of workers is determined on the basis of the amount of work per shift. Thus, if one shift fails to accomplish the task, additional staff is involved in the work; 4) expenses for fuel and lubricants. They can be determined on the basis of guidelines; 5 ) the sum of depreciation deductions. It is included in the production cost (prime cost) of products and thus is reflected in the price. The manufacturer is 
obliged to accumulate depreciation deductions, saving them from the proceeds from the products sold; 6 ) the cost of purchasing spare parts for the machine system. They can be calculated on the basis of component lists of manufacturing plants; 7) the prime cost of one cubic meter of harvested wood. It is determined as the ratio of the logging costs to the actual volume of harvested sawlogs; 8) the amount of capital investment. When calculating the investment, the following shall be taken into account: equipment transportation and installation costs, inventory and instruments cost, as well as disposal fee; 9) transportation and procurement costs, equipment dismantling costs. They are set at a rate of $10 \%$ of the cost of equipment; 10) the cost of necessary tools, fixtures and inventory taken in the amount of $3 \%$ of the cost of equipment and construction works; 11) the disposal fee for the purchase of new equipment is calculated based on the data of the list of types and categories of machines; 12) the economic efficiency coefficient. It is calculated as the ratio of net profit to capital investment.

Based on the results of the evaluation of the economic efficiency of the machine systems, the one with the best performance is selected.

In order to optimize the wood outflow route, it is suggested to use the graph method [13]. The removal of wood from the forest area to the delivery point can be represented as a transport network - a connected oriented graph $G=(V, E)$, where $V$ is the vertex set of $x$ $(i=1, \ldots, n), E$ is the arcs set $\left(x_{i}, x_{j}\right)$. One of the vertices corresponds to a forest plot (source $s$ ), the other - to delivery point (stock $t$ ), the rest - to intermediate points; the arcs correspond to the sections of the roads connecting these points. Each arc $\left(x_{i}, x_{j}\right)$ of the graph corresponds to a nonnegative value $u_{i j}$, called the carrying capacity of the arc, and the flow $f_{i j}$ - to the amount of cargo carried through the given section. In addition, each arc corresponds to a nonnegative value $c_{i j}$ - the cost of transportation of a flow unit along the arc. The carrying capacity uij of $\left(x_{i}, x_{j}\right)$ arc of the transport network determines the largest value of the flow that can flow along this arc [11].

Due to the fact that the carrying capacity of arcs, the cost of transporting a flow unit along the arc and the flow $q$, which is required to be transported through the network, cannot be precisely known in real conditions and vary depending on the period $\theta$ in which the transportation is carried out, it is necessary to consider fuzzy values $\tilde{u}_{i j}(\theta), \widetilde{c}_{i j}(\theta), \widetilde{f}_{i j}(\theta), \widetilde{q}$

Since the parameters of the arcs are fuzzy values, which depend on the period of flowing along the arc, the problem is finding the minimum transportation cost from the source of a specified amount of flow in a fuzzy dynamic transport network $\widetilde{G}=(V, \widetilde{E})[5-]$. In the graph under consideration $\widetilde{G}=(V, \widetilde{E}) \widetilde{E}$ there is a fuzzy set of arcs, where the fuzzy carrying capacity of the arc is applied as the degree of belonging of $\mu_{\widetilde{E}}\left(x_{i}, x_{j}\right)$ of the arc $\left(x_{i}, x_{j}\right)$ to the set $\tilde{E}[11]$, and the time of flow along the $\operatorname{arc}\left(x_{i}, x_{j}\right)$ is not explicitly specified, but is taken into account when determining its carrying capacity. In addition, a time horizon $T=\{1, \ldots, p\}$ is defined, which determines that all units of the flow sent from the source must arrive to the stock no later than in the period $p$.

$$
\begin{aligned}
& \sum_{\theta=1}^{p} \sum_{\left(x_{1}, x_{j}\right) \in \tilde{E}} \tilde{c}_{i j}(\theta) \tilde{f}_{i j}(\theta) \rightarrow \min \\
& \sum_{\theta=1}^{p}\left(\sum_{x_{i} \in \tilde{A}\left(x_{i}\right)} \widetilde{f}_{i j}(\theta)-\sum_{x_{k} \in A^{-1}\left(x_{i}\right)} \widetilde{f}_{k j}(\theta)\right)=\widetilde{q}, x_{i}=s: \\
& \sum_{\theta=1}^{p}\left(\sum_{x_{j} \in \tilde{A}\left(x_{i}\right)} \tilde{f}_{i j}(\theta)-\sum_{x_{k} \in \tilde{A}^{-1}\left(x_{i}\right)} \tilde{f}_{k i}(\theta)\right)=\tilde{0}, x_{i} \neq s \\
& \sum_{\theta=1}^{p}\left(\sum_{x_{j} \in \tilde{A}\left(x_{i}\right)} \tilde{f}_{i j}(\theta)-\sum_{x_{k} \in \tilde{A}^{-1}\left(x_{i}\right)} \widetilde{f}_{k i}(\theta)\right)=-\widetilde{q}, x_{i}= \\
& \widetilde{0} \leq \widetilde{f}_{i j}(\theta) \leq u_{i j}(\theta), \forall\left(x_{i}, x_{j}\right) \in \widetilde{E}, \theta \in T,
\end{aligned}
$$

The mathematical model of the problem has the following form [12]:

where $\widetilde{q}$ is a specified fuzzy flow value in the transport network, which does not exceed the maximum flow;

$\widetilde{O}$ is a fuzzy value of the form $(0,0,0)$, which reflects the absence of the flow;

$\tilde{A}\left(x_{i}\right)$ is a vertex set, the arcs from the vertex xi go to;

$\tilde{A}^{-1}\left(x_{i}\right)$ is a vertex set, the arcs to the vertex xi go from.

Equation (2) means that the specified amount of flow $\widetilde{q}$ for $p$ time periods is equal to the total flow leaving the source for $p$ time periods. Equation (4) shows that the flow for $p$ time periods is equal to the total flow entering the stock for $p$ time periods. The total amount of flow entering the source for $p$ time periods is equal to the total amount of flow leaving the stock for $p$ time periods. Equation (3) states that the amount of flow that flows into any vertex $x i$, except for the source and stock, for $p$ time periods, is equal to the amount of flow flowing from the vertex i. Limitation (5) indicates that the flows for all time periods should not exceed the carrying capacity of the corresponding arcs [11].

A transition from a specified fuzzy dynamic graph $\bar{G}=(V, \tilde{E})$, "time-stretched" for $p$-period, to fuzzy static graph $\bar{G}_{p}=\left(V_{p}, \tilde{E}_{p}\right)$ by creating a copy of each vertex $x_{i} \in V$ in each period of time is carried out. Thus, the vertex set of the graph $\bar{G}_{p}$ is given as $V_{p}=\left\{\left(x_{i}, \theta\right):\left(x_{i}, C\right) \in V x T\right\}$. The set $\tilde{E}_{p}$ consists of arcs coming from each "vertex-time" pair $\left(x_{i}, \theta\right) \in V_{p}$ to each "vertex -time" pair $\left(x_{i}, \theta+1\right)$ $\in V_{p}$ and $\left(x_{j}, \theta\right)$, where $x_{j} \in \breve{A}\left(x_{i}\right)$. Carrying capacities of arcs $\tilde{U}\left(x_{i}, x_{i}, \theta, \theta+1\right)$ connecting pairs $\left(x_{i}, \theta\right)$ and $\left(x_{i}, \theta+1\right)$ equal $\infty$, 
and the transportation costs of the flow unit along these arcs equal $\widetilde{0}$. Carrying capacities of $\operatorname{arcs} \tilde{u}\left(x_{i}, x_{j} \theta\right)$, connecting pairs $\left(x_{i}, \theta\right)$ and $\left(x_{j}, \theta\right)$, equal $\tilde{u}_{i j}(\theta)$, and the cost of transporting a flow unit is $\check{C}_{i j}(\theta)$ [11]. Artificial source $\mathrm{s}^{\prime}$ and stock t'.s' are introduced and joined by fictitious arcs, which have infinite carrying capacity and zero cost, with all true sources, and $\mathrm{t}^{\prime}$ - with all true stocks [11].

We determine the lowest costing flow from to applying Busacker-Gowen method [12], which uses the Bellman-Ford algorithm in the search for the shortest path [10]. The rules for handling fuzzy triangular numbers are presented in [12]. The algorithm finishes when a flow equal to the specified value is found in the network.

Volumes of wood transportation depend on the climatic conditions prevailing in the region. The volumes of wood transportation in central regions of Krasnoyarsk Krai are highly dependent on the season. It is suggested to divide a year into five periods: winter, winter-spring, spring, summer, autumn.
The main purpose of each wood transportation road is to remove the planned volume of wood at the set time, at the lowest cost of production possible, with the maximum use of the car fleet [12].

The main indicator determining the division of wood transportation roads into categories should be the value of carrying capacity. Carrying capacity means the maximum number of cars that a section of the road is capable of carrying within a unit of time in one or two directions subject to the road and weather conditions in question.

\section{RESULTS AND ITS DISCUSSION}

The presented methods were tested at the Gremuchinskoe logging site (LS) located in the central part of the Krasnoyarsk Krai. This site is being developed by the Novoyeniseiskiy Wood-Chemical Complex (Lesosibirsk city). In order to determine whether the introduction of the developed measures increases the value of availability of wood, a comprehensive evaluation of

Table 1: Evaluation of the impact of the developed measures the availability of wood raw material of Gremuchinskoe LS

\begin{tabular}{|l|c|c|c|}
\hline \multirow{2}{*}{ Indicators } & \multicolumn{3}{c|}{ Developed measures } \\
\cline { 2 - 4 } & $1^{*}$ & $2^{* *}$ & $3^{* * *}$ \\
\hline Assessment of available wood resources, million RUB. & $3,807.39$ & $5,172.77$ & $4,417.32$ \\
\hline Volume of available wood resources, thousand m3 & $21,870.23$ & $26,093.45$ & $23,831.01$ \\
\hline Specific assessment of available wood resources, RUB/m3 & 174.09 & 198.24 & 185.36 \\
\hline Number of plots with available wood resources, pcs. & 151 & 180 & 164 \\
\hline Assessment of unavailable wood resources, million RUB. & $-1,709.29$ & $-1,141.87$ & $-1,406.64$ \\
\hline Volume of unavailable wood resources, thousand m 3 & $15,837.07$ & $11,613,85$ & $13,876.29$ \\
\hline Specific assessment of unavailable wood resources, RUB/m3 & -107.93 & -98.32 & -101.37 \\
\hline Number of plots with unavailable wood resources, pcs. & 109 & 80 & 96 \\
\hline
\end{tabular}

${ }^{*}$ Involvement of logging waste in the production process.

** Selection of the most efficient machines system.

${ }^{* * *}$ Choosing the most efficient route for delivery of wood raw materials.

Table 2: Analysis of the change in the availability of wood raw material of Gremuchinskoe LS when implementing the developed measures

\begin{tabular}{|l|c|c|c|c|}
\hline Indicators & $1^{*}$ & $2^{* *}$ & Change & Change, $\%$ \\
\hline Assessment of available wood resources, million RUB. & $1,863.68$ & $5,523.60$ & $3,659.92$ & 196.38 \\
\hline Volume of available wood resources, thousand m3 & $12,481.12$ & $28,717.88$ & $16,236.76$ & 130.09 \\
\hline Specific assessment of available wood resources, RUB/m3 & 149.32 & 192.34 & 43.02 & 28.81 \\
\hline Number of plots with available wood resources, pcs. & 86 & 198 & 112 & 130.09 \\
\hline Assessment of unavailable wood resources, million RUB. & $-3,242.32$ & -892.74 & $2,349.58$ & -72.47 \\
\hline Volume of unavailable wood resources, thousand m 3 & $25,226.18$ & $8,989.42$ & $-16,236.76$ & -64.36 \\
\hline Specific assessment of unavailable wood resources, RUB/m3 & -128.53 & -99.31 & 29.22 & -22.73 \\
\hline Number of plots with unavailable wood resources, pcs. & 174 & 62 & -112 & -64.36 \\
\hline
\end{tabular}

* Initial value.

${ }^{* *}$ Final value. 
the availability of wood raw material of Gremuchinskoe LS was carried out taking into account the effect of the measures (Table 1, 2).

The results of the assessment show that the availability of timber resources increased by $30 \%$, and their cost increased by $96.38 \%$. In addition, specific assessment of available wood has increased by $28.81 \%$. The number of plots, which can be considered as available, has increased to 20 (by 20 pieces). Accordingly, the number of plots with unavailable wood decreased, and their value decreased.

\section{CONCLUSION}

Approbation of the presented techniques on the basis of a large logging site of Krasnoyarsk Krai showed that they are efficient. It is also important to take into account the fact that every entity engaged in logging industry has limited resources (personnel, raw materials, finances, materials, etc.). In these conditions, there is a need to select the measures that provide the greatest positive effect. This effect may be expressed in the growth of production, increase of profits, increase of the efficiency of the use of fixed assets, reduction of harmful impact on the environment, etc. The suggested methods for implementing technological measures meet these requirements and may be implemented at enterprises of the region's wood industry complex.

\section{ACKNOWLEDGEMENT}

The reported study was funded by Russian Foundation for Basic Research, Government of Krasnoyarsk Territory, Krasnoyarsk Regional Fund of Science, to the research project: «Research and modeling of economic development of the forest industry in the region in the context of climatic conditions and resource potential», grant № 18-410-240003

\section{REFERENCES}

1. Tretyakov, A.G. (2015). Estimation of Economic Accessibility of Forest Resources and Processing of Low-quality Wood. Bulletin of Omsk University. Series: Economy, No 1. P. 142-149.

2. Mokhirev, A.P., Pozdnyakova, M.O., Medvedev, S.O., Mammatov, V.O. (2018). Assessment of availability of wood resources using geographic information and analytical systems (the Krasnoyarsk Territory as a case study). Journal of Applied Engineering Science, 16(3), 313-319. doi:10.5937/jaes16-16908

3. Pozdnyakova, M.O., Mokhirev, A.P. (2018). Algorithm for Assessing the Availability of Wood Resources, Taking into Account Environmental, Technological, Technical, Transport and Economic Constraints: Innovations in the Chemical and Forestry Complex. In Trends and Development Prospects - Proceedings of the All-Russian Scientific and Practical Conference. Krasnoyarsk. P. 68-73.
4. Knyazeva, G.A. (2005). Economic Accessibility of the Forest Resources of the Komi Republic: Corporate Management and Innovative Development of the Economy of the North. Bulletin of the SIC of Corporate Law, Management and Venture Investment of the Syktyvkar State University, Issue 4, P. 56-60.

5. Tretyakov, A.G. (2014). Efficiency of Wood Consumption in the Wood Industry and Economic Accessibility of Forest Resources: Economic Sciences. Issue 119, P. 29-33.

6. Efremov, M.A. (2009). Transport Accessibility of Forests as the Main Factor in the Level of Use of Forest Resources. Bulletin of the Mari State Technical University. Series: Economics and Management, No 1. P. 60-66.

7. Mokhirev, A.P. (2007). Substantiation of Designing a Network of Forest Roads Based on the Example of the Enterprises of the Lower Angara Region: Thesis for a Candidate Degree in Technical Sciences. 05. 21. 01. Krasnoyarsk. 176 p.

8. Mokhirev, A.P., Pozdnyakova, M.O., Kunitskaya, O.A., Grigorev, I.V. (2018). Factors of Wood Resources Availability: Analysis of their Impact on Key Criteria. Systems. Methods. Technologies, Issue 1 (37), P. 110-115; http://brstu.ru/static/unit/journal_ smt/docs/number-37/110-115.pdf..

9. Mokhirev, A.P., Yu. Bezrukih, A., \& Medvedev, S.O. (2015). Processing of Wood Waste of Logging Enterprises as a Factor of Sustainable Nature Management. Engineering Bulletin of the Don, No 2, Part 2. URL: ivdon.ru/en/magazine/archive/ n2p2y2015/3011.

10. Mammatov V.O., Mokhirev A.P, (2017). Methodology for the Formation of a System of Logging Machines. Forestry Engineering Journal, 7(1), 111-117. doi:10.12737/25201 URL: http://lestehjournal.ru/ journal/2017/no-1/metodika-formirovaniya-sistemy-lesozagotovitelnyh-mashin

11. Borozna, A.A., Salminen, E.O. (2004). Current Condition and Problems of Forestry Complex: (based on International Forestry Summit). Russian Federation, St. Petersburg, SPb: Ministry of Education and Science of the, State Forest Technical Academy -: SPbGLTA. 39 p.

12. Romanov, E.S. (2006). Structurization of the Concept of Accessibility of Forest Resources. Forestry Journal, No 3. P. 121-126.

13. Burkatovskaya, Y.B. (2014). Graph Theory. Part 1: Study guide. Tomsk: Tomsk Polytechnic University. 200 p.

Paper submitted: 17.11.2018.

Paper accepted: 11.08.2018.

This is an open access article distributed under the CC BY-NC-ND 4.0 terms and conditions. 